\title{
Chemotherapy Improves Survival After Percutaneous Biliary Drainage in Patients With Pancreatic or Biliary Tract Cancer With Biliary Obstruction
}

\author{
JARMO NIEMELÄ ${ }^{1}$, HANNU SYRJÄLÄ ${ }^{2}$, PASI OHTONEN ${ }^{3,4}$, JUHA SAARNIO ${ }^{1}$ and RAIJA KALLIO ${ }^{5}$ \\ ${ }^{1}$ Department of Surgery, Oulu University Hospital and Medical Research Center, Oulu, Finland; \\ ${ }^{2}$ Department of Infection Control, Oulu University Hospital, Oulu, Finland; \\ ${ }^{3}$ Division of Operative Care, Oulu University Hospital, Oulu, Finland; \\ ${ }^{4}$ Research Unit of Surgery, Anesthesiology and Intensive Care, University of Oulu, Oulu, Finland; \\ ${ }^{5}$ Department of Oncology, Oulu University Hospital, Oulu, Finland
}

\begin{abstract}
Background: The survival benefit of chemotherapy compared to best supportive care (BSC) after percutaneous transhepatic biliary drainage (PTBD) was evaluated in patients with pancreatic or biliary tract cancer. Patients and Methods: A retrospective registry study was conducted at a tertiary-level university hospital. The endpoint was survival measured from the PTBD and the initiation of chemotherapy. Results: Among 158 patients ( $m e a n$ age $=74$ years, range $=43$ 93 years; $51.9 \%$ women), 82 (51.9\%) had pancreatic cancer and $76(48.1 \%)$ had biliary tract cancer. After PTBD, 32 (20.3\%) patients received chemotherapy and had a median survival of 11.7 months; 126 (79.7\%) patients received only $B S C$ resulting in a median survival of 1.7 months. The hazard ratio for survival at 1 year for patients who received chemotherapy compared to BSC was 0.22 (95\% confidence interval=0.12-0.41, $p<0.001)$. Conclusion: After PTBD, patients with pancreatic or biliary tract cancer should be critically evaluated by an oncologist to determine whether chemotherapy is possible, as it seems to significantly improve survival compared to BSC.
\end{abstract}

Hyperbilirubinemia due to malignant biliary obstruction is quite common in patients with advanced pancreatic and biliary tract cancer and the oncological treatment is challenging $(1,2)$. The first choice for the treatment of

This article is freely accessible online.

Correspondence to: Jarmo Niemelä, Department of Surgery, Oulu University Hospital, Box 21, FIN-90029 OYS, Oulu, Finland. Tel: +358 83152011, e-mail: Jarmo.Niemela@ppshp.fi

Key Words: Cancer, chemotherapy, hyperbilirubinemia, biliary obstruction, percutaneous biliary drainage. malignant biliary obstruction worldwide is endoscopic biliary drainage. Percutaneous transhepatic biliary drainage (PTBD) is a treatment option when endoscopic drainage is not feasible due to duodenal obstruction or previous surgery, or has been insufficient. These patients with PTBD had usually unfavorable outcome; in our retrospective series, the median overall survival after PTBD was 2.6 months (3).

New chemotherapy combinations have shown a positive trend of prolonged survival in patients with pancreatic and biliary tract cancer (4-7). However, hyperbilirubinemia caused by biliary obstruction precludes the administration of chemotherapy, and these patients have typically been excluded from clinical studies $(4,5,8)$. There are very limited data concerning the utility of chemotherapy for this patient group with malignant biliary obstruction not suitable for endoscopic biliary drainage and therefore treated with PTBD (9-12).

In the present study, we investigated the benefit of chemotherapy compared to best supportive care after PTBD in patients with pancreatic or biliary tract cancer with hyperbilirubinemia caused by biliary obstruction.

\section{Patients and Methods}

A detailed description of the entire study population of 643 patients was published previously (3). The study protocol was approved by our Institution's Ethics Committee (no. 140/2011). This retrospective subanalysis included patients with chemotherapy-naïve pancreatic or biliary tract cancer with malignant biliary obstruction who were treated with PTBD and followed-up at a tertiary-level university hospital between 2003 and 2016. Full electronic medical records, including chemotherapy records, were available for that time period.

All drainage procedures were performed with the patient under anesthesia. The procedure was performed by experienced interventional radiologists guided by ultrasonography and fluoroscopy according to previously documented methods (13). A self-expanding metal stent was inserted in $125(79.1 \%)$ patients, and external drainage was used in $33(20.9 \%)$ patients. 
Table I. Demographics and clinical characteristics of 158 patients with pancreatic or biliary tract cancer according to therapy after percutaneous transhepatic biliary drainage. Data represent the number of patients (\%) unless otherwise noted.

\begin{tabular}{|c|c|c|c|c|}
\hline Characteristic & & $\begin{array}{l}\text { Chemotherapy } \\
(\mathrm{n}=32,20.3 \%)\end{array}$ & $\begin{array}{l}\text { Best supportive care } \\
\quad(\mathrm{n}=126,79.7 \%)\end{array}$ & $p$-Value ${ }^{\mathrm{a}}$ \\
\hline Age, years & Mean \pm SD (range) & $68 \pm 7.4(52-82)$ & $76 \pm 9.2(49-93)$ & $<0.001^{b}$ \\
\hline Gender & Male & $22(68.8)$ & $50(39.7)$ & $0.003^{\mathrm{a}}$ \\
\hline \multirow[t]{3}{*}{ Comorbidities } & 0 & $13(40.6)$ & $34(27.0)$ & $0.16^{\mathrm{a}}$ \\
\hline & $1-2$ & $15(46.9)$ & $59(46.8)$ & \\
\hline & $>2$ & $4(12.5)$ & $33(26.2)$ & \\
\hline \multirow[t]{2}{*}{ Type of cancer } & Pancreatic & $17(53.1)$ & $65(51.6)$ & $0.88^{\mathrm{a}}$ \\
\hline & Biliary tract & $15(46.9)$ & $61(48.4)$ & \\
\hline \multirow[t]{3}{*}{ ASA class } & $1-2$ & $12(37.5)$ & $21(16.7)$ & $0.008^{\mathrm{a}}$ \\
\hline & 3 & $20(62.5)$ & $89(70.6)$ & \\
\hline & 4 & $0(0)$ & $16(12.7)$ & \\
\hline \multirow[t]{3}{*}{ ECOG PS } & $0-1$ & $27(84.4)$ & $34(27.0)$ & $<0.001^{\mathrm{a}}$ \\
\hline & 2 & $4(12.5)$ & $46(36.5)$ & \\
\hline & $3-4$ & $1(3.1)$ & $46(36.5)$ & \\
\hline \multirow[t]{3}{*}{ Level of bile duct obstruction } & Upper (hilum) & $12(37.5)$ & $47(37.3)$ & $0.53^{\mathrm{a}}$ \\
\hline & Middle (common hepatic duct) & $8(25.0)$ & $22(17.5)$ & \\
\hline & Lower (common bile duct) & $12(37.5)$ & $57(45.2)$ & \\
\hline
\end{tabular}

ASA class: American Society of Anesthesiologists physical status classification; SD, standard deviation; ECOG PS, Eastern Cooperative Oncology

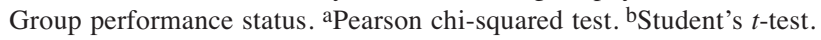

The patient population was divided into two groups: Patients eligible to receive chemotherapy, and those treated with only best supportive care after PTBD. We compared the outcomes of these patient groups and the following data were retrieved from the electronic medical records: Age, sex, pre-procedure American Society of Anesthesiologists physical status classification class (14), Eastern Cooperative Oncology Group performance status (ECOG PS) (15), comorbidities, type of cancer, and serum bilirubin level. We recorded the highest bilirubin value observed in the 7 days before the procedure, and the lowest value in the 30 days after the procedure and at the time of evaluation by an oncologist.

Time of death was acquired from death certificates (Statistics Finland) (16). Survival was defined as the interval starting from the PTBD in the group treated with best supportive care, and the initiation of chemotherapy in the chemotherapy-treated group, and ending with the patient's death or last follow-up.

Statistical analysis. Statistical analyses were performed using SPSS Statistics for Windows, Version 25.0 (IBM Corp, Armonk, NY, USA). Summary data are presented as means with standard deviation, or as medians with $25-75^{\text {th }}$ percentiles (interquartile range, IQR). Between-group comparisons were performed by Student's $t$-test or Welch test for continuous data, and the chisquared test or Fisher's exact test for categorical data. The log-rank test was used to compare survival times in univariate analyses. We used a multivariable adjusted time-dependent Cox proportional hazards model to avoid and minimize the immortal time bias to determine the impact of chemotherapy treatment on the 1-year survival rate (17). To minimize biases and validate patient groups in the multivariable model, we constructed a directed acyclic graph (DAG) to derive a minimally sufficient adjustment set. The DAG was drawn using the DAGitty tool (18). The DAGitty model indicated that the following parameters should be taken into account in the adjusted Cox model: Patient age $(\leq 70,>70$ years), number of co-morbidities (none, 1-2, >2), ECOG PS (0-1, 2, 3-4), bilirubin level after drainage $[<60, \geq 60 \mu \mathrm{mol} / 1$; according to a receiveroperating characteristic curve from our previous study (3)], and the type of cancer (pancreatic or biliary tract). The results of the Cox model are presented as hazard ratios and $95 \%$ confidence intervals. Two-tailed $p$-values are reported.

\section{Results}

The study group comprised 158 patients, of which 82 $(51.9 \%)$ had pancreatic cancer and $76(48.1 \%)$ had biliary tract cancer. The diagnosis of cancer was verified by histology in $40(25.3 \%)$ patients, by cytology in $88(55.7 \%)$ patients and by radiology in $30(19.0 \%)$ patients. The median time from cancer diagnosis to drainage was 0.3 months $\left(25^{\text {th }}-75^{\text {th }}\right.$ percentiles $0.2-0.7$ months).

Patient demographics and clinical characteristics are presented in Table I. The mean age for the whole cohort was 74 years (range=49-93 years). A low American Society of Anesthesiologists class $(p=0.008)$ and low ECOG PS grade $(p<0.001)$ were more common in the chemotherapy group than in the best supportive care group (Table I). The chemotherapy group had a higher proportion of males than the best supportive care group $(p=0.003)$, while patients in the best supportive care group were older than those in the chemotherapy group $(p<0.001)$.

After PTBD, 62 (39.2\%) patients were evaluated by an oncologist. Their median bilirubin level after PTBD was 33.5 $\mu \mathrm{mol} / \mathrm{L}(\mathrm{IQR}=18.8-52.8 \mu \mathrm{mol} / \mathrm{l})$. Thirty-two $(51.6 \%)$ of these 
Niemelä et al: Chemotherapy After Percutaneous Drainage of Malignant Biliary Obstruction

Table II. Outcome after percutaneous transhepatic biliary drainage (PTBD) in 158 patients with pancreatic or biliary tract cancer.

\begin{tabular}{|c|c|c|c|c|}
\hline Therapy after PTBD & Subgroup & $\begin{array}{l}\text { Median }(95 \% \mathrm{CI}) \\
\text { survival, months }\end{array}$ & $\begin{array}{c}\text { Survival at } \\
1 \text { year, } \mathrm{n}(\%)\end{array}$ & $p$-Value \\
\hline \multirow{3}{*}{ Chemotherapy $(n=32,20.3 \%)$} & Overall & $11.7(9.0-14.5)$ & $15(46.9)$ & \multirow[t]{6}{*}{$<0.001^{\mathrm{a}}$} \\
\hline & Pancreatic cancer $(\mathrm{n}=17,53.1 \%)$ & $11.2(10.2-12.1)$ & $7(41.2)$ & \\
\hline & Biliary tract cancer $(\mathrm{n}=15,46.9 \%)$ & $15.1(5.2-25.0)$ & $8(53.3)$ & \\
\hline \multirow[t]{3}{*}{ Best supportive care $(n=126,79.7 \%)$} & Overall & $1.7(1.2-2.2)$ & $9(7.1)$ & \\
\hline & Pancreatic cancer $(n=65,51.6 \%)$ & $1.3(0.6-2.1)$ & $3(4.6)$ & \\
\hline & Biliary tract cancer $(\mathrm{n}=61,48.4 \%)$ & $1.9(1.2-2.6)$ & $6(9.8)$ & \\
\hline
\end{tabular}

aLog-rank test between patient groups treated with chemotherapy, and with best supportive care after PTBD.

62 patients received chemotherapy, while 30 patients $(48.4 \%)$ did not receive chemotherapy for the following reasons: 16 patients had ECOG PS 3, 10 patients had ECOG PS 4 and four patients with ECOG PS 1-2 refused chemotherapy. Ninety-six patients from the study population were not evaluated by an oncologist and their median bilirubin level after PTBD was $90.0 \mu \mathrm{mol} / \mathrm{l}(\mathrm{IQR}=45.5-229.0$ $\mu \mathrm{mol} / \mathrm{l}$; missing values for 11 patients). The main exclusion criteria for evaluation of chemotherapy in addition to high bilirubin level were poor performance status, advanced disease, age, co-morbidities, and patient refusal.

Among the $32(20.3 \%)$ patients who received chemotherapy, $17(53.1 \%)$ had pancreatic cancer and 15 $(46.9 \%)$ had biliary tract cancer (Table I). The corresponding figures in the best supportive care group were $65(51.6 \%)$ and $61(48,4 \%)$, respectively. The median time for the initiation of chemotherapy after PTBD was 1.8 months (IQR=0.7-4.6 months). Single-agent gemcitabine was the first-line treatment for $76 \%(13 / 17)$ of patients with pancreatic cancer and $73 \%(11 / 15)$ of patients with biliary tract cancer. Combination chemotherapy was given to $24 \%$ (4/17) of patients with pancreatic cancer (gemcitabine with oxaliplatin or erlotinib, etoposide with cisplatin, or fluorouracil with oxaliplatin and irinotecan) and 27\% (4/15) of patients with biliary tract cancer (gemcitabine with cisplatin). Only two patients with pancreatic cancer and one patient with biliary tract cancer received a second-line treatment. No patient received a third-line treatment.

The median survival of the 32 chemotherapy-treated patients was 11.7 months, and $15(46.9 \%)$ patients were alive at 1 year after PTBD $(p<0.001$; Table II, Figure 1$)$. Both cancer groups gained significant survival benefits with chemotherapy, with a median survival of 11.2 months for the pancreatic cancer group and 15.1 months for the biliary tract cancer group. The median survival of the 126 patients treated with best supportive care was 1.7 months $(p<0.001$; Table II, Figure 1); 2.0 months in patients with ECOG PS 0-2, and 0.9 months with ECOG PS $3-4(p=0.216)$. Nine $(7.1 \%)$ of the patients with best supportive care were alive at 1 year after PTBD.
According to the time-dependent multivariable adjusted Cox regression model, the hazard ratio for survival at 1 year was 0.22 (95\% confidence interval $=0.12-0.41, p<0.001)$ for patients who received chemotherapy compared to patients who received best supportive care.

\section{Discussion}

Our results showed that patients with pancreatic or biliary tract cancer and malignant biliary obstruction treated with PTBD and thereafter chemotherapy had significantly better survival compared to those treated with best supportive care after drainage. In all but one of the previous PTBD studies (19), information concerning chemotherapy was brief, with few or no details about the regimens $(9,11,20)$, and the focus has mainly been on the technical aspects of biliary drainage.

In a recent, retrospective study from South Korea including patients with hilar cholangiocarcinoma, chemotherapy was given to 34 patients and best supportive care to 74 patients after drainage (12). In this study, the standard chemotherapy for biliary tract cancer was gemcitabine combined with cisplatin. This combination treatment has been associated with a significant survival advantage compared to gemcitabine alone, without substantial toxicity (5). In our biliary tract cancer group ( $\mathrm{n}=15$ patients), only four patients received this combination; while 11 patients received gemcitabine alone. In the South Korean study (12), the median survival was 12.8 months for the chemotherapytreated group and 6.1 months for the best supportive care group. In our series, the median survival was 15.1 months for patients with biliary tract cancer who received chemotherapy after PTBD and 1.9 months for those who received best supportive care. The outcomes may have been even better for our patients with biliary tract cancer if the gemcitabinecisplatin combination had been used more widely.

In our study, 13 out of 17 patients $(76 \%)$ with pancreatic cancer received gemcitabine alone as a first-line treatment. Recently, the combination of nab-paclitaxel and gemcitabine was shown in post-hoc registry analyses to significantly 


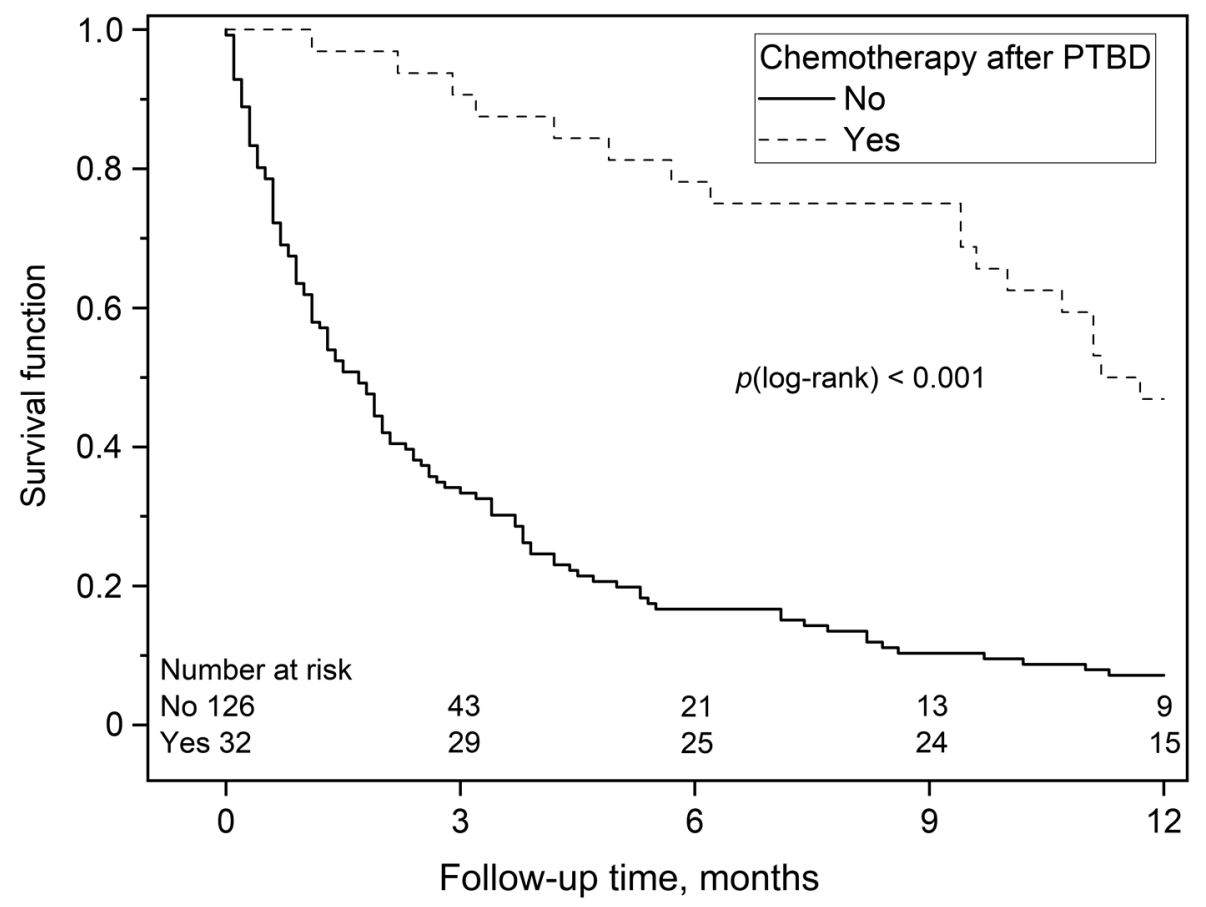

Figure 1. Kaplan-Meier survival analysis of 158 patients with pancreatic or biliary tract cancer according to therapy after percutaneous transhepatic biliary drainage $(P T B D)$.

improve the outcome of patients with locally advanced and metastatic pancreatic cancer (6). The median survival of our patients with pancreatic cancer treated with chemotherapy was 11.2 months and with best supportive care 1.3 months. The survival figures with the use of the combination therapy would have been even better (21).

A high bilirubin level can diminish hepatic clearance and alter drug metabolism, increasing toxicity; therefore, hyperbilirubinemia has been considered an exclusion criterion for chemotherapy $(8,22)$. Limited knowledge is available regarding appropriate chemotherapy dosing and management in patients with higher bilirubin levels. Treatment recommendations for patients with hyperbilirubinemia have been based on small phase I studies or retrospective patient series with heterogeneous study populations (4, 5, 8, 23-26). It has been reported that an initial dose reduction is unnecessary for widely used gemcitabine or capecitabine in patients with biliary tract or pancreatic cancer after successful management of biliary obstruction, even with moderate hyperbilirubinemia $(27,28)$. Chemotherapy may be considered even with higher bilirubin levels than in daily practice (i.e., $<1.5$-fold the upper limit of the normal range) (29). An ongoing prospective phase I trial (AIO-PAK-0117 PANCHO) is evaluating the safety and efficacy of a combination of nabpaclitaxel and gemcitabine in patients with metastatic pancreatic cancer and hyperbilirubinemia (21).
There are several ways of calculating survival in different study designs. Recently, much attention has been paid to immortal time bias, i.e., the time between diagnosis and the initiation of cancer treatment, which researchers should be aware of to avoid misleading conclusions concerning the benefits of therapy (30-33). For example, in the South Korean study with hilar cholangiocarcinoma (12), survival was calculated from the date of cancer diagnosis to death or the last follow-up. Using a similar definition, the survival of our patients with biliary tract cancer would have been 18.1 months instead of 15.1 months, which was calculated from the initiation of chemotherapy to avoid immortal time bias.

The main strength of our study was that we included all patients treated with PTBD for malignant biliary obstruction due to pancreatic or biliary tract cancer at the same teaching hospital. To the best of our knowledge, this was the first study analyzing the benefit of chemotherapy in patients with malignant biliary obstruction after PTBD including both pancreatic and biliary tract cancer, the most common causes of malignant hyperbilirubinemia. To avoid misleading conclusions, we constructed a DAG to examine biases related to all possible causal variables $(18,34)$, and used the time-dependent multivariable analysis, which is accurate in estimating treatment effects and includes all patients in the study $(17,30)$. According to the DAGitty model, a multivariable adjusted, time-dependent Cox regression model 
was adjusted for patient age, number of co-morbidities, ECOG PS, bilirubin level after PTBD and the type of cancer. This approach gave a hazard ratio of 0.22 (95\% confidence interval=0.12-0.41) for survival at 1 year after PTBD for patients who received chemotherapy, with median survival of 11.7 months compared to 1.7 months for patients who received best supportive care. In the latter group, the survival difference between those with ECOG PS 0-2 and ECOG PS 3-4 was only 1 month.

Our study was a single-center, retrospective study, similar to most previous studies on this topic. During the study period, only one-fifth of the patients in our series received chemotherapy after PTBD. According to the latest knowledge concerning hyperbilirubinemia and chemotherapy $(21,35)$, more patients in our supportive care group would have been eligible to receive and benefit from chemotherapy after PTBD, therefore, an oncological evaluation is important to identify patients eligible for chemotherapy.

\section{Conclusion}

Our results show that patients with pancreatic or biliary tract cancer with hyperbilirubinemia should be critically evaluated by an oncologist after PTBD to determine whether chemotherapy is possible. This approach seems to improve survival significantly compared to best supportive care in these patients. Further studies are needed for developing appropriate guidelines for chemotherapy in patients with cancer with hyperbilirubinemia.

\section{Conflicts of Interest}

The Authors have no conflicts of interest to declare. The Authors had full control of all primary data and agree to allow the journal to review their data if requested.

\section{Authors' Contributions}

JN: Study design; collection of data; quality control of data; data analysis; article preparation, editing, and review. HS, PO, JS, RK: Study design; quality control of data; data analysis; article preparation, editing, and review.

\section{References}

1 Ryan DP, Hong TS and Bardeesy N: Pancreatic adenocarcinoma. N Engl J Med 371(11): 1039-1049, 2014. PMID: 25207767. DOI: $10.1056 /$ NEJMra1404198

2 Jansen H, Pape UF and Utku N: A review of systemic therapy in biliary tract carcinoma. J Gastrointest Oncol 11(4): 770-789, 2020. PMID: 32953160. DOI: 10.21037/jgo-20-203

3 Niemelä J, Kallio R, Ohtonen P, Perälä J, Saarnio J and Syrjälä $\mathrm{H}$ : Is palliative percutaneous drainage for malignant biliary obstruction useful? World J Surg 42(9): 2980-2986, 2018. PMID: 29536143. DOI: 10.1007/s00268-018-4567-0
4 Conroy $\mathrm{T}$, Desseigne F, Ychou M, Bouché O, Guimbaud R, Bécouarn Y, Adenis A, Raoul JL, Gourgou-Bourgade S, de la Fouchardière C, Bennouna J, Bachet JB, Khemissa-Akouz F, PéréVergé D, Delbaldo C, Assenat E, Chauffert B, Michel P, MontotoGrillot C, Ducreux M, Groupe Tumeurs Digestives of Unicancer. and PRODIGE Intergroup: FOLFIRINOX versus gemcitabine for metastatic pancreatic cancer. N Engl J Med 364(19): 1817-1825, 2011. PMID: 21561347. DOI: 10.1056/NEJMoa1011923

5 Valle J, Wasan H, Palmer DH, Cunningham D, Anthoney A, Maraveyas A, Madhusudan S, Iveson T, Hughes S, Pereira SP, Roughton M, Bridgewater J and ABC-02 Trial Investigators: Cisplatin plus gemcitabine versus gemcitabine for biliary tract cancer. N Engl J Med 362(14): 1273-1281, 2010. PMID: 20375404. DOI: 10.1056/NEJMoa0908721

6 Kieler M, Unseld M, Bianconi D, Schindl M, Kornek GV, Scheithauer W and Prager GW: Impact of new chemotherapy regimens on the treatment landscape and survival of locally advanced and metastatic pancreatic cancer patients. J Clin Med 9(3): 648, 2020. PMID: 32121198. DOI: $10.3390 / \mathrm{jcm} 9030648$

7 Rizzo A, Ricci AD, Tober N, Nigro MC, Mosca M, Palloni A, Abbati F, Frega G, DE Lorenzo S, Tavolari S and Brandi G: Second-line treatment in advanced biliary tract cancer: today and tomorrow. Anticancer Res 40(6): 3013-3030, 2020. PMID: 32487595. DOI: 10.21873 /anticanres. 14282

8 Vogel A, Kullmann F, Kunzmann V, Al-Batran SE, Oettle H, Plentz R, Siveke J, Springfeld C and Riess H: Patients with advanced pancreatic cancer and hyperbilirubinaemia: review and German expert opinion on treatment with nab-paclitaxel plus gemcitabine. Oncol Res Treat 38(11): 596-603, 2015. PMID: 26599274. DOI: $10.1159 / 000441310$

9 Afshar M, Khanom K, Ma YT and Punia P: Biliary stenting in advanced malignancy: an analysis of predictive factors for survival. Cancer Manag Res 6: 475-479, 2014. PMID: 25525389. DOI: $10.2147 /$ CMAR.S71111

10 Mahgerefteh S, Hubert A, Klimov A and Bloom AI: Clinical impact of percutaneous transhepatic insertion of metal biliary endoprostheses for palliation of jaundice and facilitation of chemotherapy. Am J Clin Oncol 38(5): 489-494, 2015. PMID: 24064748. DOI: 10.1097/COC.0b013e3182a5341a

11 Li M, Bai M, Qi X, Li K, Yin Z, Wang J, Wu W, Zhen L, He C, Fan D, Zhang Z and Han G: Percutaneous transhepatic biliary metal stent for malignant hilar obstruction: results and predictive factors for efficacy in 159 patients from a single center. Cardiovasc Intervent Radiol 38(3): 709-721, 2015. PMID: 25338831. DOI: 10.1007/s00270-014-0992-0

12 Shin DW, Kim MJ, Lee JC, Kim J, Woo SM, Lee WJ, Lee KH and Hwang $\mathrm{JH}$ : Gemcitabine plus cisplatin chemotherapy prolongs the survival in advanced hilar cholangiocarcinoma: a large multicenter study. Am J Clin Oncol 43(6): 422-427, 2020. PMID: 32118610. DOI: 10.1097/COC.0000000000000682

13 Sutter CM and Ryu RK: Percutaneous management of malignant biliary obstruction. Tech Vasc Interv Radiol 18(4): 218-226, 2015. PMID: 26615162. DOI: 10.1053/j.tvir.2015.07.005

14 American Society of Anesthesiologists: ASA physical classification system. Available at: https://www.asahq.org/resources/clinicalinformation/asa-physical-status-classification-system [Last accessed January 1, 2021]

15 Eastern Cooperative Oncology Group: ECOG performance status. Available at: http://ecog-acrin.org/resources/ecogperformance-status [Last accessed January 1, 2021] 
16 Statistics Finland. Available at: https://www.stat.fi [Last accessed January 1, 2021]

17 Agarwal P, Moshier E, Ru M, Ohri N, Ennis R, Rosenzweig K and Mazumdar M: Immortal time bias in observational studies of time-to-event outcomes: assessing effects of postmastectomy radiation therapy using the National Cancer Database. Cancer Control 25(1): 1073274818789355, 2018. PMID: 30021466. DOI: $10.1177 / 1073274818789355$

18 Textor J, van der Zander B, Gilthorpe MS, Liskiewicz M and Ellison GT: Robust causal inference using directed acyclic graphs: the R package 'dagitty'. Int J Epidemiol 45(6): 18871894, 2016. PMID: 28089956. DOI: 10.1093/ije/dyw341

19 Dhondt E, Vanlangenhove P, Geboes K, Vandenabeele L, Van Cauwenberghe L and Defreyne L: No evidence of improved efficacy of covered stents over uncovered stents in percutaneous palliation of malignant hilar biliary obstruction: results of a prospective randomized trial. Eur Radiol 30(1): 175-185, 2020. PMID: 31385047. DOI: 10.1007/s00330-019-06374-7

20 Crosara Teixeira M, Mak MP, Marques DF, Capareli F, Carnevale FC, Moreira AM, Ribeiro U Jr, Cecconello I and Hoff PM: Percutaneous transhepatic biliary drainage in patients with advanced solid malignancies: prognostic factors and clinical outcomes. J Gastrointest Cancer 44(4): 398-403, 2013. PMID: 23760941. DOI: 10.1007/s12029-013-9509-3

21 Pelzer U, Wislocka L, Jühling A, Striefler J, Klein F, RoemmlerZehrer J, Sinn M, Denecke T, Bahra M and Riess H: Safety and efficacy of Nab-paclitaxel plus gemcitabine in patients with advanced pancreatic cancer suffering from cholestatic hyperbilirubinaemia-A retrospective analysis. Eur J Cancer 100: 85-93, 2018. PMID: 30014884. DOI: 10.1016/j.ejca.2018.06.001

22 Field KM and Michael M: Part II: Liver function in oncology: towards safer chemotherapy use. Lancet Oncol 9(12): 11811190, 2008. PMID: 19038765. DOI: 10.1016/S14702045(08)70307-3

23 Álvarez R, Carrato A, Adeva J, Alés I, Prados S, Valladares M, Macarulla T, Muñoz A and Hidalgo M: Management of hyperbilirubinaemia in pancreatic cancer patients. Eur J Cancer 94 : 26-36, 2018. PMID: 29505968. DOI: 10.1016/j.ejca.2018.01.078

24 Dierks J, Gaspersz MP, Belkouz A, van Vugt JLA, Coelen RJS, de Groot JWB, Ten Tije AJ, Meijer WG, Pruijt JFM, van Voorthuizen T, van Spronsen DJ, Rentinck M, Ten Oever D, Smit JM, Otten HM, van Gulik TM, Wilmink JW, Groot Koerkamp B and Klümpen H: Translating the ABC-02 trial into daily practice: outcome of palliative treatment in patients with unresectable biliary tract cancer treated with gemcitabine and cisplatin. Acta Oncol 57(6): 807-812, 2018. PMID: 29265948. DOI: $10.1080 / 0284186 X .2017 .1418532$

25 Lamarca A, Benafif S, Ross P, Bridgewater J and Valle JW: Cisplatin and gemcitabine in patients with advanced biliary tract cancer $(\mathrm{ABC})$ and persistent jaundice despite optimal stenting: Effective intervention in patients with luminal disease. Eur J Cancer 51(13): 1694-1703, 2015. PMID: 26066735. DOI: 10.1016/j.ejca.2015.05.018
26 Rogers JE, Mizrahi JD, Shroff RT, Nelson DA, Tu J, Javle MM, Wolff RA and Pant S: Dose-modified gemcitabine plus nabpaclitaxel front-line in advanced pancreatic ductal adenocarcinoma with baseline hyperbilirubinemia. J Gastrointest Oncol 11(1): 5560, 2020. PMID: 32175105. DOI: 10.21037/jgo.2019.10.05

27 Joerger M, Huitema AD, Koeberle D, Rosing H, Beijnen JH, Hitz F, Cerny T, Schellens JH and Gillessen S: Safety and pharmacology of gemcitabine and capecitabine in patients with advanced pancreatico-biliary cancer and hepatic dysfunction. Cancer Chemother Pharmacol 73(1): 113-124, 2014. PMID: 24166106. DOI: 10.1007/s00280-013-2327-2

28 Shibata T, Ebata T, Fujita K, Shimokata T, Maeda O, Mitsuma A, Sasaki Y, Nagino $M$ and Ando Y: Optimal dose of gemcitabine for the treatment of biliary tract or pancreatic cancer in patients with liver dysfunction. Cancer Sci 107(2): 168-172, 2016. PMID: 26595259. DOI: $10.1111 /$ cas.12851

29 European Society for Medical Oncology: ESMO Clinical Practise Guidelines. Available at: http://www.esmo.org/ Guidelines [Last accessed January 1, 2021]

30 Newman NB, Brett CL, Kluwe CA, Patel CG, Attia A, Osmundson EC and Kachnic LA: Immortal time bias in National Cancer Database studies. Int J Radiat Oncol Biol Phys 106(1): 512, 2020. PMID: 31404580. DOI: 10.1016/j.ijrobp.2019.07.056

31 Suissa S: Immortal time bias in pharmaco-epidemiology. Am J Epidemiol 167(4): 492-499, 2008. PMID: 18056625. DOI: 10.1093/aje/kwm324

32 Mi X, Hammill BG, Curtis LH, Lai EC and Setoguchi S: Use of the landmark method to address immortal person-time bias in comparative effectiveness research: a simulation study. Stat Med 35(26): 4824-4836, 2016. PMID: 27350312. DOI: 10.1002/ $\operatorname{sim} .7019$

33 Verma V, Wegner RE, Brooks ED, Miccio JA, Kann BH, Finley GG, Raj MS, Grover S, Mohindra P and Simone CB 2nd: Chemotherapy versus supportive care for unresected malignant pleural mesothelioma. Clin Lung Cancer 20(4): 263-269, 2019. PMID: 30992187. DOI: 10.1016/j.cllc.2019.03.003

34 Etminan M, Collins GS and Mansournia MA: Using causal diagrams to improve the design and interpretation of medical research. Chest 158(1S): S21-S28, 2020. PMID: 32658648. DOI: 10.1016/j.chest.2020.03.011

35 Martín AM, Hidalgo M, Alvarez R, Arrazubi V, Martínez-Galán J, Salgado M, Macarulla T and Carrato A: From first line to sequential treatment in the management of metastatic pancreatic cancer. J Cancer 9(11): 1978-1988, 2018. PMID: 29896283. DOI: $10.7150 /$ jca. 23716
Received February 3, 2021

Revised April 23, 2021

Accepted April 27, 2021 